\title{
Simple Method for Preparing Delicate Dinoflagellate of the Genus Amphidinium for Scanning Electron Microscopy
}

Hugo Pérez-López ${ }^{1}$, Lorena Durán-Riveroll ${ }^{2}$, Laura E. Gómez-Lizárraga ${ }^{3}$ and M. Berenit MendozaGarfias $^{1}$

${ }^{1}$ Universidad Nacional Autónoma de México, Mexico, Distrito Federal, Mexico, ${ }^{2}$ CICESE, Ensenada, Baja California, Mexico, ${ }^{3}$ Instituto de Ciencias del Mar y Limnología, Universidad Nacional Autónoma de México, Mexico, Distrito Federal, Mexico

Dinoflagellates are common in all aquatic ecosystems and important part of all of them as primary producers. They are bi-flagellated unicellular organisms that range between 10 and $400 \mu \mathrm{m}$ in length [1]. Some of them are potentially toxic and can be responsible of great losses in fisheries, death of marine mammals, birds and mollusks, and cause important human intoxications, such as paralytic shellfish poisoning (PSP), ciguatera fish poisoning (CFP), diarrhetic shellfish poisoning (DSP), and many other more [2]. Members of the genus Amphidinium have been related to CFP because they are often found living in close relationship with the dinoflagellates proven to be the CFP-toxin-producers, but human toxicity caused by Amphidinium spp. has not been documented. However, these dinoflagellates are confirmed producers of outstanding molecules with biological activities, such as antifungal and hemolytic polyhydroxy-polyene polyketides [3], macrolides like amphidinolides and iriometeolides with cytotoxic properties [4] and are probable sources of other interesting anti-cancer agents [5].

Members of the genus Amphidinium are dorsoventrally flattened cells with a minute, triangular or leftdeflected epicone [6]. They are "athecate" or "naked" because they lack thecal cellulose plates, and this makes their cells extremely delicate [7]. This characteristic complicates their preservation and the observation of their morphological features through scanning electron microscopy (SEM), mainly because sample preparation protocols, from fixation, dehydration and physical drying often destroy or distort the cells.

In order to provide and facilitate Amphidinium spp. sample preparation methodology for SEM, a brief protocol has been prepared, describing the technique used for the treatment of monoclonal cultures from different coastal regions of Mexico (Gulf of Mexico, Caribbean Sea, and Gulf of California).

For chemical fixation, $15 \mathrm{~mL}$ of well-established cell cultures in exponential growth (two weeks), were centrifuged $\left(35 \times \mathrm{g}, 24^{\circ} \mathrm{C}\right.$, for 5 minutes). A $750 \mu \mathrm{L}$ subsample of this concentrated material was fixed with $750 \mu \mathrm{L}$ of osmium tetroxide $\left(\mathrm{OsO}_{4}\right)$ at a final concentration of $2 \%$ in distilled water at room temperature $\left(24^{\circ} \mathrm{C}\right)$, for $90 \mathrm{~min}$. After cell fixation, samples were centrifuged and washed four times $(800$ $\times \mathrm{g}, 4^{\circ} \mathrm{C}$, for 3 minutes) with $1.0 \mathrm{~mL}$ of cold $\left(4{ }^{\circ} \mathrm{C}\right)$ distilled water, followed by dehydration with a graded ethanol (EtOH) series (10, 20, 30, 40, 50, 60, 70, 80, 90 and 99\%, $1 \mathrm{~mL}$ each). Ethanol was added to the microtubes and cells were gently resuspended for $1 \mathrm{~min}$. Then, they were centrifuged (same parameters as in sample washing) and the supernatant was removed. This process was repeated in each dehydration step. After $99 \%$ EtOH was removed, $200 \mu \mathrm{L}$ of a hexamethyldisilazane:ethanol (HMDS:EtOH) solution 1:1 v/v was added. Cells were gently resuspended as before and centrifuged as in previous steps. Lastly, $200 \mu \mathrm{L}$ of pure HMDS were added, the cells were gently resuspended, and the sample was placed on the SEM stubs. The stubs were left for air-drying in a hood for $12 \mathrm{~h}$ and were gold sputter-coated for 5 minutes.

The use of $\mathrm{OsO}_{4}$ as primary fixative permeabilizes membranes and stabilizes cells, preventing cell damage from osmotic changes during subsequent treatments [8]. In addition, due to its chemical nature as a 
transition metal, it improves the resolution for observation of biological samples. HMDS reduces surface tension and shrinkage of cells by giving strength to the sample by cross-linked proteins [9].

The protocol we are proposing not only prevents cell distortion and damage, but it is also a low-cost treatment, since there is fewer chemical reagents consumption, like buffers or secondary fixative solutions. Additionally, there is no need to filter the material into polycarbonate membranes or the use of glass coverslips, like in common protocols $[9,10]$. Furthermore, the use of cultures allows to select organisms of a known growth time (in this case two weeks), so that formation of external mucous membranes that cover the surface and morphological features of the cells can be prevented, and so the use of detergents like Triton X-100 will not be necessary [11].

This preparation method is fast, simple and effective, which are important advantages for effective SEM observation of well-preserved external morphology features of Amphidinium spp. (Plate 1).

\section{Acknowledgments}

We thank Dra. Reyna Lara-Martínez of the department of cellular biology of the Faculty of Sciences, UNAM for their support in the adequate use, manipulation and preparation of $\mathrm{OsO}_{4}$, and Dr. Fernando González-Farías, Martín López-Hernández and Ana Luisa Mejía-Camacho from the Laboratory of Environmental Chemistry for their help and support in sample preparation. 


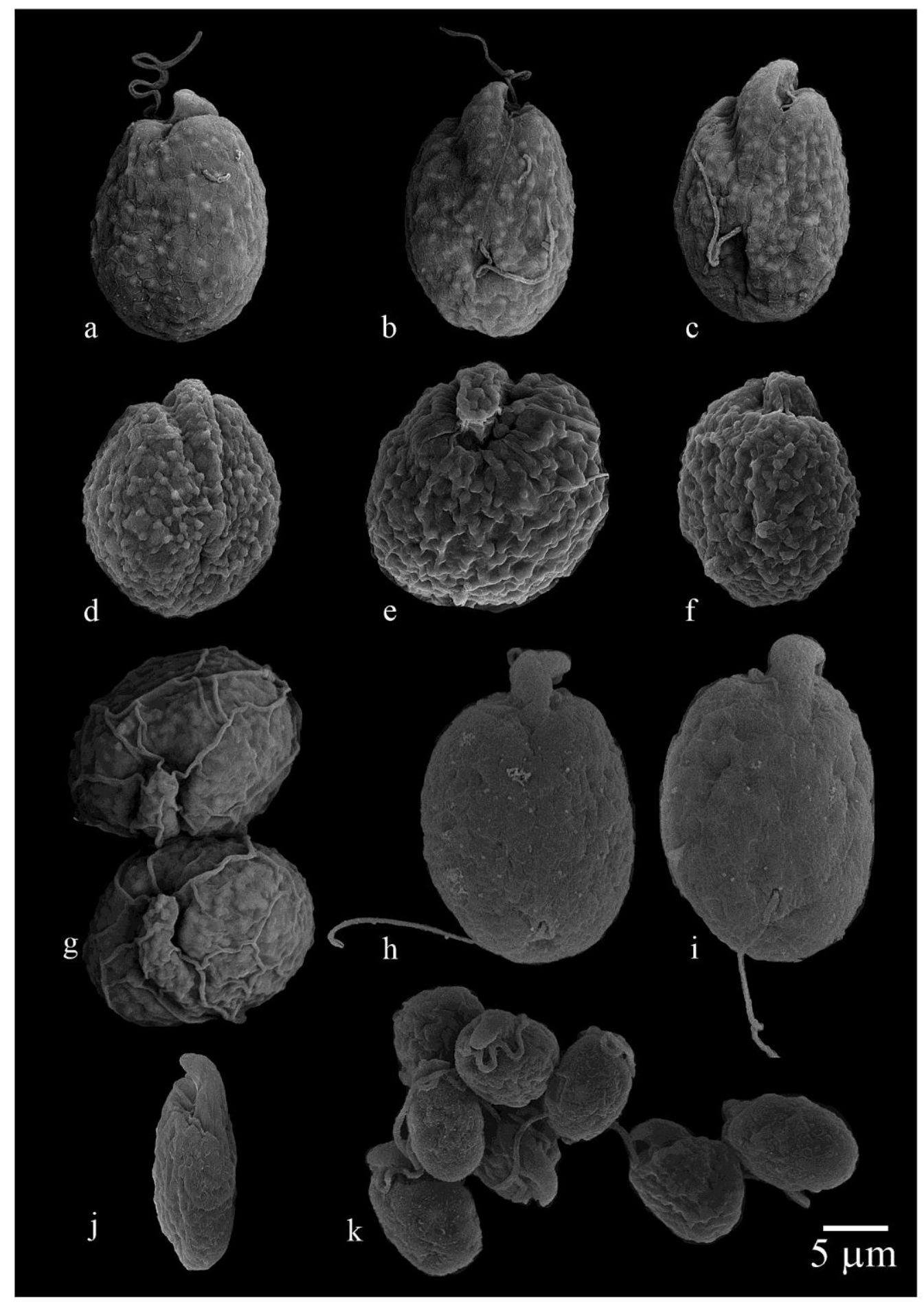

Figure 1. Scanning electron micrographs of Amphidinium spp. after the applied preparation technique, from culture collection at the Marine Biotechnology Department, CICESE: AA38 (a to g), AA60 (h and i), AA115 (j) and AA112 (k). Cell shape in dorsal view (a) and dorsal-lateral view (f and j). Flagellar 
insertion and biflagellate cells in ventral view (b, c, d, h and i). Shape of the epicone in apical-dorsal view (e) and apical-lateral view (g). A group of cultured athecate dinoflagellate cells showing good morphological preservation $(\mathrm{k})$. Parameters of scanning electron micrographs in BES (acc. voltage: $8 \mathrm{kV}$, WD: $15 \mathrm{~mm}$, images a to g) and in SE (acc. voltage: $10 \mathrm{kV}$, WD: 10-19 mm, images $\mathrm{h}$ and $\mathrm{k}$ ) taken with SEM JEOL JSM-6360LV and Hitachi-SU 1510.

\section{References}

[1] S. Carty and M. W. Parrow, (2015), Dinoflagellates, Amsterdam, Elsevier.

[2] P. Lassus, et. al., (2016), Toxic and harmful microalgae of the World Ocean, Denmark, UNESCO.

[3] G. Nuzzo et al., Journal of Natural Products 77, 6 (2014), p. 1524-1527.

[4] M. Akakabe et al., Chemical and Pharmaceutical Bulletin 64, 7 (2016), p. 1019-1023.[5] R. A. Espiritu et al., Jordan Journal of Biological Sciences 10 (2017), p. 297-302.

[6] R. J. Orr et al., Plos One 7, 11 (2012), p.e5004

[7] C. L. Morrill, et. Al., International Review Cytology 82 (1983) p. 151-181

[8] E. W. Truby, Microscopy Research and Technique 36 (1997), p. 337-340.

[9] S. Won Jung et al., Journal of Applied Phycology 22 (2010), p. 313-317.

[10] L. Botes et al., Microscopy Research and Technique 59 (2002), p.128-130.

[11] L. Mason et al., Journal of Phycology 39 (2003), p. 253-258. 